\title{
How does Merendera montana (L.) Lange (Liliaceae) benefit from being consumed by mole-voles?
}

\author{
Daniel Gómez-García ${ }^{1, *}$, José Azorín ${ }^{1}$, Stella M. Giannoni ${ }^{2}$ and Carlos E. Borghi ${ }^{2}$ \\ ${ }^{1}$ Instituto Pirenaico de Ecología (CSIC), Apdo. 64, Jaca, E-22700, Huesca, España; ${ }^{2}$ IADIZA (CONICET), \\ GIB, CC. 507, Mendoza, 5500, Argentina; *Author for correspondence
}

Received 19 March 2002; accepted in revised form 7 February 2003

Key words: Alkaloid concentration, Animal-plant interaction, Geophytes, Protocooperation, Subterranean rodents

\begin{abstract}
The relationships between a geophyte (Merendera montana (L.) Lange - Liliaceae) and a mole-vole (Microtus duodecimcostatus de Sélys-Longchamps) in the Spanish Pyrenees were investigated by analysing plant density, asexual reproductive strategies, and chemical composition of $M$. montana, and by observing the feeding behavior of $M$. duodecimcostatus in captivity. We found that M. montana contains toxic alkaloids, the concentration of which varies throughout the year; being minimal at the end of the vegetative period. Alkaloids are stored in the whole plant, particularly in the leaves which are scarcely consumed by herbivores. Nevertheless, mole-voles eat this plant profusely both in the field and in captivity, where they showed preference for the corm. The corm has lower alkaloid concentration and higher levels of energetic substances than the other plant parts, particularly leaves. Although corm consumption causes plant death, M. montana grows more abundantly in areas colonized by mole-voles than in undisturbed grasslands with high plant cover and absence of mole-vole populations. Both asexual reproduction and seedlings of this species are more frequent in highly disturbed areas. Results strongly suggest a protocooperative relationship between mole-voles and this geophyte: the burrowing behavior of molevoles favours dispersal and reproductive success of the plant, enhancing its habitat availability; the plant in turn supplies abundant and nutritious food at a low and "acceptable" toxicity cost.
\end{abstract}

\section{Introduction}

The influence of rodents on vegetation and particularly on grasslands has been a much discussed topic in plant ecology (Summerhayes 1941), as was the effect of disturbances caused by burrowing mammals on the structure and dynamics of plant communities (Collins and Barber 1985; Harper 1977; Hobbs and Hobbs 1987; Huntly and Inouye 1988; Hobbs and Mooney 1991; Huntly and Reichman 1994; Reichman and Jarvis 1989; Sousa 1984). On the other hand, some relationships between a few plants and subterranean rodents, showing adaptive behaviors to their mutual advantage, have also been described, nearly all of them in subdesert areas of Israel and Africa (Brett 1991; Galil 1967; Lovegrove and Jarvis 1986).

In recent studies of mole-voles (genus Microtus Schrank) in the Spanish Pyrenees, we showed that these burrowing animals influence plant composition, plant community structure, and seed dispersal (Gómez-García et al. 1995, 1999). Furthermore, we found a strong decrease in plant cover and dominant species coupled with an increase in geophyte abundance in areas inhabited by mole-voles (GómezGarcía et al. 1995), which suggested some sort of relationship between these organisms. In fact, in the South of Spain, it has been found that mole-voles feed extensively on the storage organs of several geophytes, which can represent over $90 \%$ of their diet (Soriguer and Amat 1980).

In general, geophytes contain a considerable and well-stored quantity of nutrients in the corm, which makes them an excellent food resource for many animals, especially for subterranean mammals (Bennett and Jarvis 1995). Moreover, these are also asexual reproductive propagules, which, just like seeds, get 
dispersed. However, as part of their defenses against herbivores, many geophytes are toxic and unpalatable, or have developed different physical defences against herbivores (Lovegrove and Jarvis 1986; Watt and Breyer-Brandwijk 1962). This is the case of different plant species of the subfamily WURMBEOIDEAE Thunb. (LILIACEAE Juss.) (Ornithoglossum Salisb., Androcymbium Willd., Wurmbaea Thunb.) that contain different tropolonic alkaloids, such as colchicine, 3-demethylcolchicine and colchicoside, in the whole plant, provoking poisoning and death of cattle that feed on them (Pijewska et al. 1967).

Several geophytes occur in the montane and subalpine pastures of the Pyrenees, such as Narcissus L. spp, Scilla verna Hudson, Corydalis solida (L.) Clairv., Bulbocodium vernum L. and Merendera montana (L.) Lange. The two last species belong to the family LILIACEAE Juss., and also contain tropolonic alkaloids, chiefly colchicine (Santavy 1957; Kaul et al. 1964). Merendera montana (L.) Lange, is a perennial plant endemic to the Iberian Peninsula, which reaches its northernmost limit of distribution on the northern side of the Pyrenees. In spite of its narrow area of distribution, $M$. montana, is a common and widespread plant which lives in all types of sheepgrazed pastures.

Just like several other geophytes adapted to the oromediterranean climate, M. montana shows "hysteranthous foliage" which means that this plant flowers without bearing leaves (Dafni et al. 1981). Because of this phenological behavior, no aerial organs are present in summer when, in the alpine mountains, the majority of other species of plants are growing and flowering. By the end of the summer, while the rest of the vegetation starts senescence, a new subterranean corm of $M$. montana, (Figure 1a) produces an unique flower (August-September) and, immediately after, three or four leaves surface and stay greens up to the end of the following spring. The subterranean ovary takes several months $(8-10)$ to develop a mature capsule which dehisces in May-June of the next year, coinciding with leaf senescence. Seed dispersal occurs in the summer, while the corm remains dormant. Nevertheless, on some occasions capsules do not reach the surface, and then seeds can germinate "in situ" (Figure 1c) producing a clump of seedlings and young plants (Figure 1d). Flowering marks the beginning of a yearly life cycle of a new storage organ which will be replaced with another the following year. Similarly to the related genus Colchicum L.
(Poutaraud and Champay 1995), it seems that the lifespan of $M$. montana, extends to twenty or more cycles, and that the first bloom does not appear until the plant reaches the age of five. M. montana, also reproduces asexually by developing a bud from the apex of the old corm, which can easily separates from the mother plant giving way to a new individual (Figure $1 \mathrm{~b}$ ).

M. montana contains the same tropolonic alkaloids formerly cited for another plant genus of the subfamily WURMBEOIDEAE. These alkaloids are well known for their cytotoxic effects, and provoke vomiting, diarrhoea and miscarriage in vertebrates, including rats (Farnsworth et al. 1975; Paris and Moyse 1967). In fact, M. montana, despite being the most abundant geophyte in Pyrenean pastures between 800 and $2000 \mathrm{~m}$ of altitude, and one of the very few species that show green leaves during the winter, is seldom eaten by herbivores, except at the end of spring, when some leaves appear bitten by chamois (Rupicapra rupicapra pyrenaica Bonaparte; García-González and Montserrat 1986).

Nonetheless, M. montana, is highly consumed by mole-voles which peel off and discard the tannin-rich tunics and eat the corm (Borghi and Giannoni 1997). Tannins are digestion inhibitors that could badly disrupt a gut detox mechanism. Rejected corm tunics are present in great numbers, mixed together with disturbed soil in areas inhabited by mole-vole colonies (personal observation). On the other hand, these mole-voles could have microsomal enzymes in their liver for detoxification of the alkaloids, or have a gut flora that eats these alkaloids as has been reported in the case of other small mammals (Freeland and Janzen 1974). Although consumption of its corm leads to plant death, M. montana, grows more abundantly in areas with mounds and burrows. The apparent contradiction between high consumption and local abundance of this plant encouraged us to study this molevole/geophyte relationship by analysing the density, dispersal strategies and chemical composition of $M$. montana, and by observing the feeding behavior of Microtus duodecimcostatus in captivity. Essentially, we have tried to answer the following questions:

1. Are plant and seedlings of M. montana more abundant in grassland areas disturbed by mole-voles than in neighbouring undisturbed ones?

2. Is asexual reproduction of M. montana similar in disturbed and undisturbed plots?

3. Is alkaloid concentration uniform in all parts of the 
a
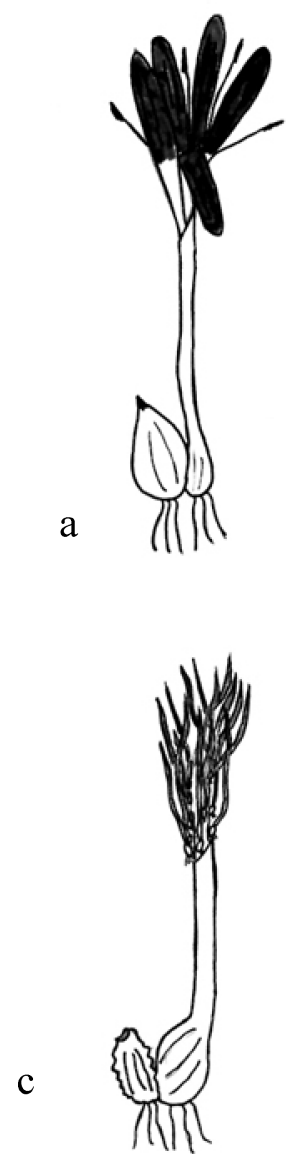
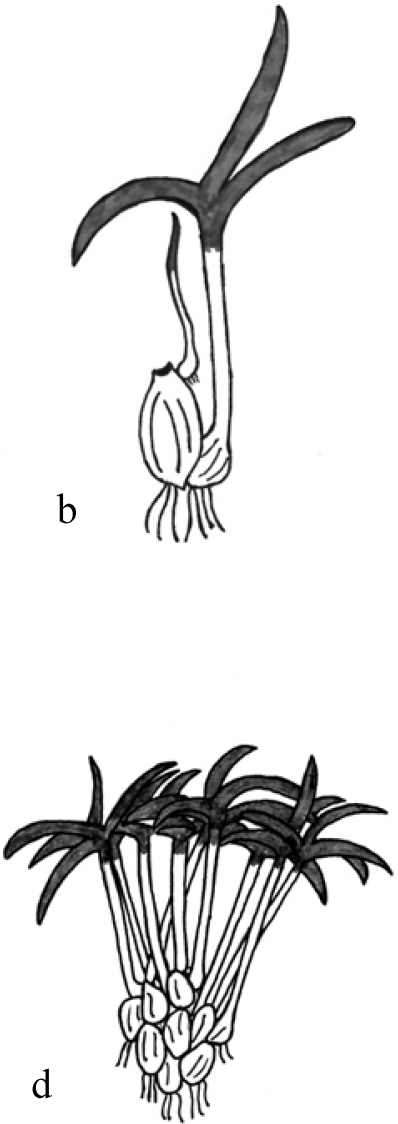

Figure 1. a) flowering shoot of $M$. montana showing the corm of the former year; b) new shoot of $M$. montana emerging from asexual reproduction; c; young colony of $M$. montana seedlings resulting from "in situ" germination of seeds, d) colony or neighbourhood of young plants of M. montana

\section{plant?}

4. Does this alkaloid concentration vary throughout the year?

5. Do mole voles prefer corms, leaves or flowers?

6. Is the preference of mole-voles for M. montana related to its alkaloid content?

\section{Methods}

Field studies were conducted in 1994 near the town of Jaca, in the province of Huesca, in the Spanish Pyrenees. Samples were collected in four localities: Salto de Roldán (U.T.M.: 30TYM1581, altitude 800 m), Jaca (30TYN0016; 820 m), Cubilar de las Vacas $(30 \mathrm{TXN} 9829,1410 \mathrm{~m})$ and Cuello Arenas (31TBH5521, $1950 \mathrm{~m}$ ). These sites are representative of mediterranean, sub-mediterranean, montane and subalpine grasslands respectively. Two neighbouring
$400 \mathrm{~m}^{2}$ plots with presence (disturbed) or absence (undisturbed) of mole-vole populations were chosen at each site. Disturbed and undisturbed sites were established through the presence or lack of tunnels, mounds and removed soil.

Density of M. montana, as well as total aboveground plant cover were assessed by recording plant presence ("relevé") with the line point method (Goodall 1953). Twenty 2 -m transects were randomly sampled in each locality (10 in disturbed and 10 in undisturbed areas). Along every transect, 40 plant contacts, at $5 \mathrm{~cm}$ intervals, were gathered, thus obtaining a total of 800 points on each site (400 on disturbed sites and 400 on undisturbed ones).

For studying reproductive strategies (presence or absence of buds), 200 adult plants (100 in disturbed and 100 in undisturbed areas) were randomly collected in each locality. Since seedlings were impossible to find among the dense sward, three $\mathrm{kg}$ of soil 
Table 1. Plant cover, number of shoots of Merendera montana per $\mathrm{m}^{2}$, and total number of seedlings associated with mature plants in the different study areas, and in Disturbed (Dist.) and Undisturbed (Und.) plots.

\begin{tabular}{|c|c|c|c|c|c|c|c|c|}
\hline & \multicolumn{2}{|c|}{ S. Roldán } & \multicolumn{2}{|c|}{ Jaca } & \multicolumn{2}{|c|}{ C. Vacas } & \multicolumn{2}{|c|}{ Cuello Arenas } \\
\hline & Und & Dist & Und & Dist & Und & Dist & Und & Dist \\
\hline Plant cover $(\%)^{(1)}$ & 93 & $69 *$ & 97 & $59 *$ & 98 & $52 *$ & 100 & $24 *$ \\
\hline Shoots of M.m/m $\mathrm{m}^{2}$ (1) & 61 & $205 * *$ & 71 & $424 * *$ & 2.9 & $127 * *$ & 29 & $224 * *$ \\
\hline Total seedlings ${ }^{(2)}$ & 26 & $64 * *$ & 15 & $36^{*}$ & 12 & $29 *$ & 8 & $43 * *$ \\
\hline
\end{tabular}

(1) Mann-Whitney U Test; ${ }^{(2)}$ Binomial test. $* \mathrm{p} \leqslant 0.05 ; * * \mathrm{p} \leqslant 0.001$.

associated with plants from each plot were collected and carefully scanned, and the seedlings found were counted.

In order to ascertain the alkaloid concentration in M. montana, plants were collected in the four localities in 1994. Sampling was carried out on a monthly basis (except in July when plant is reduced to the subterranean corm) for chemical analysis. Samplings collected from April through November (in Cuello Arenas only from April to October) were used for feeding trials. Thirty individuals were collected at random over 0.25 ha. Twenty of the sampled plants were destined for preference experiments and the others to alkaloid determination. Alkaloid extraction was assessed for leaves, bulbs, and flowers (when present). Leaves, bulbs and flowers were washed, dried at $40{ }^{\circ} \mathrm{C}$, ground, and mixed with ammonia (1 $\mathrm{ml}$ of $10 \%$ ammonia solution was added to $1 \mathrm{~g}$ of each sample). Extraction was performed with $5 \mathrm{ml}$ of methanol (at room temperature for 2 hours). Later, the sample was filtered and evaporated, to finally dissolve the residue in $1 \mathrm{ml}$ of methanol. Subsequently, samples were subjected to thin layer chromatography on silicagel $60 \mathrm{~F}_{254}$ precoated TLC plates; the solvent system utilized was ethylacetate-methanol-water (100:13.5:10); pure colchicine was used as reference substance (Wagner et al. 1984). Chromatograms were developed with CLH, which colours the stains of tropolonic alkaloids (Fell and Ramsden 1966), and Dragendorff's reactive, an universal alkaloid developer. Alkaloid concentration was assessed from plates with a densitometric scanner and values were expressed as percent of dry matter.

In conducting preference experiments, four adult individuals of $M$. duodecimcostatus were used. As concerneds the sample size, It should be noted that this species shows scarce populations with very low densities (Borghi 1992). They were kept individually in $26 \times 13 \times 25$-cm cages, having access to food "ad libitum" (carrots and peanuts). Cafeteria trials were performed to determine food preference of these rodents (Krebs 1989). During the trials, $10 \mathrm{~g}$ of each item (carrots as a control item; and M. montana corms, leaves, and flowers when possible) were separately and simultaneously offered in small, easily accessible plastic jars. Items used in the trials were weighed before being offered, and kept in the cages for four hours. Later, the remaining items were collected and weighed. The weight of each consumed item was used as an indicator of relative preference (Murray and Dickman 1994). Manly's second model (variable prey populations) was used to measure preference (Krebs 1989). Manly's alpha $(\alpha)$ values were obtained for every item offered, and food items were then ranked according to these values. Cafeteria trials were performed monthly for $M$. montana collected at all sampling sites throughout the study period.

\section{Results}

Density of $M$. montana was significantly higher in disturbed than in undisturbed plots (Table 1), being 3.2 times higher in Salto del Roldan and 40 times higher in Cubilar de las Vacas. Seedling abundance was also significantly higher in disturbed plots in all study areas (Table 1). Moreover, density (number of shoots), and number of seedlings of M. montana showed a negative correlation with plant cover $\left(\mathrm{r}_{\mathrm{s}}=\right.$ $-0.84 ; \mathrm{n}=10 ; \mathrm{p}=0.002$ and $\mathrm{r}_{\mathrm{s}}=-0.83 ; \mathrm{n}=8 ; \mathrm{p}=$ 0.01 respectively). Asexual reproduction was much higher in disturbed than in undisturbed areas (Table 2).

Alkaloid concentration was different in the various plant parts. Low contents - below $0.05 \%$ in all samples - were found in the corm. Mean annual alkaloid concentration in leaves was 0.38 (\% of dry matter; SD $=0.14 ; \mathrm{n}=35)$. Presence of alkaloids was also detected in roots $(0.10 \%)$, flowers $(0.13-0.25 \%)$, and seeds $(0.30 \%)$. Annual variations in alkaloid concen- 
Table 2. Asexual reproduction (presence of vegetative buds emerging from the bulb and growing separately to generate new individuals) in Disturbed and Undisturbed plots, in the different study areas. Mann-Whitney U Test $(\mathrm{p}=0.028)$.

\begin{tabular}{lll}
\hline & Undisturbed & Disturbed \\
\hline Salto de Roldan & 7 & 21 \\
Jaca & 2 & 38 \\
Cubilar de las Vacas & 3 & 20 \\
Cuello Arenas & 0 & 48 \\
Total & 12 & 127 \\
\hline
\end{tabular}

tration in leaves are shown in Figure 2. The highest concentration was observed in a sample collected in November $(0.65 \%)$, and the lowest $(0.05 \%)$ in June.

All individuals of $M$. duodecimcostatus showed a preference for corms, followed by carrots (as a control item), and rarely leaves and flowers (Figure 3). Mean preference ranks (Manly's $\alpha$ ) for all sites were: corms $0.68>$ carrots $0.21>$ flowers $0.17>$ leaves 0.11 . In all cases, corms with their rind removed represented over $50 \%$ of the items consumed, while leaves were the least consumed of plant organs. We also found variations in the preference for corms during the course of the year. The highest preference corresponded to the autumn months, and the lowest to the summer months (Figure 3).

Concerning the relationship between mole-vole preference for leaves (Manly index) and their alkaloid concentration, we found a significant Spearman correlation $(r=-0.768, p<0.0001$; Figure 4$)$.

\section{Discussion}

Our results have shown that $M$. montana is considerably more abundant in disturbed than in neighbouring undisturbed areas. This abundance seems surprising at first, considering that mole-vole predation of corms unavoidably results in plant death. A similar pattern was found for other geophytes consumed by subterranean rodents (Galil 1967; Contreras and Gutiérrez 1991; Reichman and Jarvis 1989). Brett (1991), studying the feeding behavior of naked mole rats in arid lands of Kenia, found only one food item (the geophyte Macrotyloma maranguense (Taub.) Verdc.) whose abundance displayed a positive association with their burrows.

In our study system (mole-vole and M. montana), asexual replication by subterranean sprouts appears to be an important mechanism which, together with the dispersal of small $M$. montana storage organs by mole-voles onto soil mounds (Borghi and Giannoni 1997) and seedling recruitment, would explain the greater abundance of this plant in disturbed soil. This kind of asexual reproduction has only been previously observed - as "quite rare" - in crops of Colchicum autumnale (Poutaraud and Champay 1995). However, there are no studies on underground organs of other WURMBAEOIDEAE species, and these subterranean buds are likely to be more abundant than previously believed. Similar adaptive asexual strategies have been found in Oxalis cernua Thunb. and $M i$ cranthus (Pers.) Ecklon spp (Galil 1967; Lovegrove and Jarvis 1986). In both cases, these geophytes, with palatable food reserves, would take advantage of bulb dispersal by mole rats by displaying adaptive mechanisms such as the production of hard bulbs in the axis of the plant or weakly attached corm segments and cormlets which can be easily dislodged from the mother plant.

The fact that asexual reproduction of $M$. montana was much more frequent in highly disturbed areas allows us to suggest that soil disturbance would improve that strategy, in the same way as some Crocus L. develop lateral stolons which give rise to young corms, permitting them to replicate quickly after disturbances (Mathew 1982). Whatever the case, molevole burrowing activities would favour M. montana by spreading seeds, seedlings and asexual buds (Borghi and Giannoni 1997), and by providing a habitat with low plant competition and higher levels of fertility due to an increase in mineralization rate resulting from soil removal (Canals and Sebastià 2000).

Alkaloid concentration in M. montana, was not uniform in all plant parts, and minimum quantities were found in the corms of the populations studied compared with other plant organs. Although a great variation in concentration of secondary compounds is normal in many species, it seems paradoxical that corms, which are vital plant organs and furthermore contain desirable energetic food, should show low toxicity. An explanation is that this implies an important selective advantage for the plant. The Optimal Defence Hypothesis (McKey 1974; Rhoades 1979) predicts a high alkaloid concentration in corms to discourage animal predation. In fact, this occurs in other species of the WURMBAEOIDEAE subfamily, and particularly in Colchicum autumnale which are found in the same area and are rejected by herbivores (Ellington 1998). 


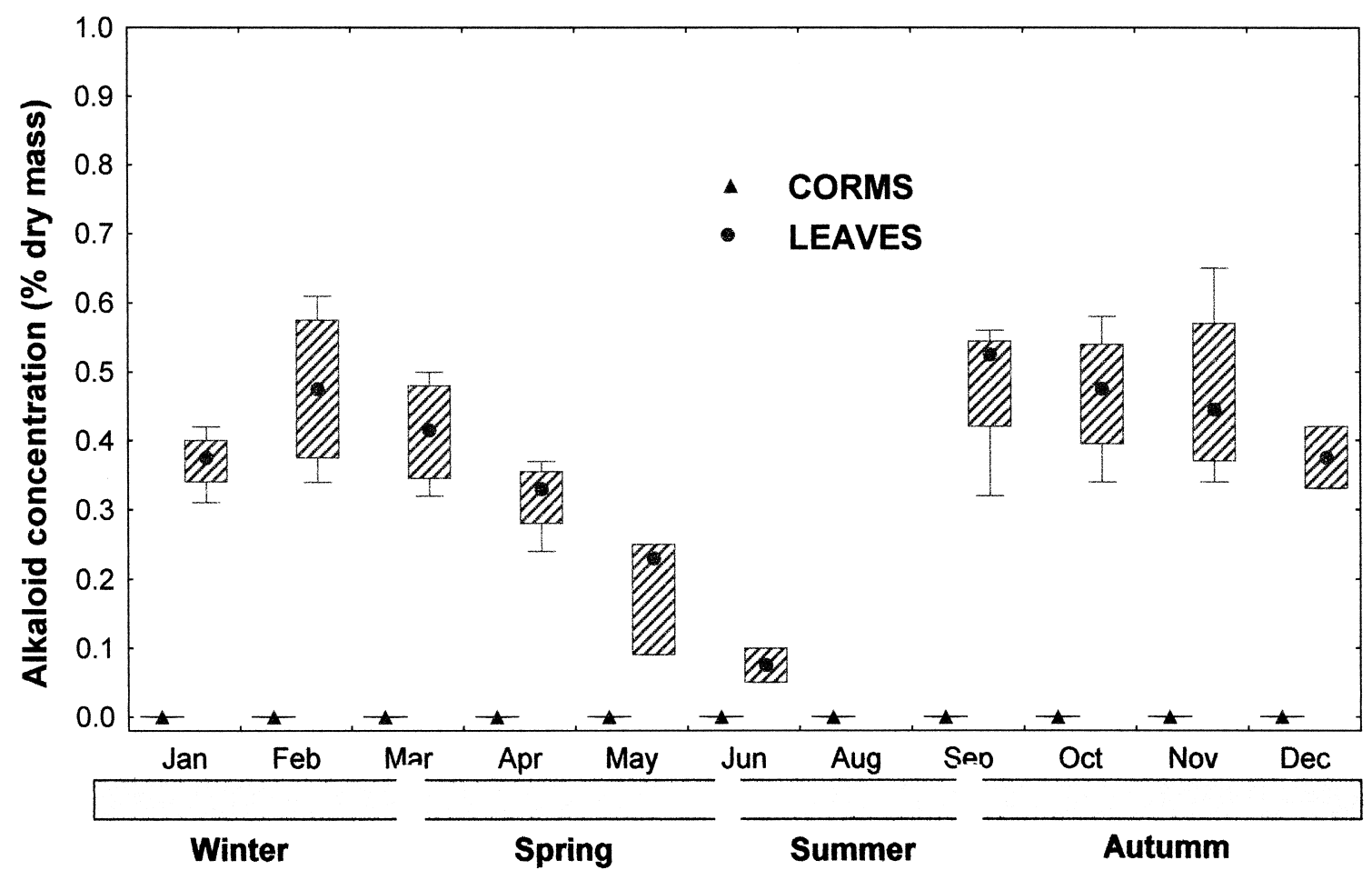

Figure 2. Annual variations in alkaloid concentration in leaves and corms. Median, 25\%, 75\%; Whisker: Non-Outlier Min, Non-Outlier Max. Concentration values are expressed as percent of dry matter.

Mole-voles always preferred bulbs in cafeteria trials, while preference for leaves was negatively associated with alkaloid concentration. This capacity to distinguish different toxic concentrations has been observed in laboratory rats that tried to avoid toxic effects by eating food containing lower amounts of chemical toxins (Freeland and Janzen 1974).

The particular phenology of this plant which shows "attractive" green leaves in spring, winter and autumn, amongst senescent vegetation of low nutritive value, along with the inability to regenerate leaves, would make it highly vulnerable to herbivory if no chemical defence were present to protect it. The high level of colchicine in leaves in this case clearly supports the "Plant Apparency Hypothesis" (Feeny 1976; Rhoades and Cates 1976). Leaf consumption by wild chamois just before senescence coincides with a drop in alkaloid concentration, which can be accounted for by the recycling of nitrogenous compounds and by the end of the vegetative period, thus causing minimum damage to the plant.

All of these results suggest that $M$. montana has developed a double strategy as regards herbivores: a high concentration of chemical deterrents in leaves to avoid aboveground predation which brings advantages (energy/structural conservation) to the plant, and a low alkaloid concentration in the bulb which allows predation by subterranean mammals to the advantage (direct reproductive/dispersal) of plant populations. We suggest a protocooperative relationship between M. montana, and M. duodecimcostatus, and whether it is evolved (or coevolved) or accidental remains to be investigated. 

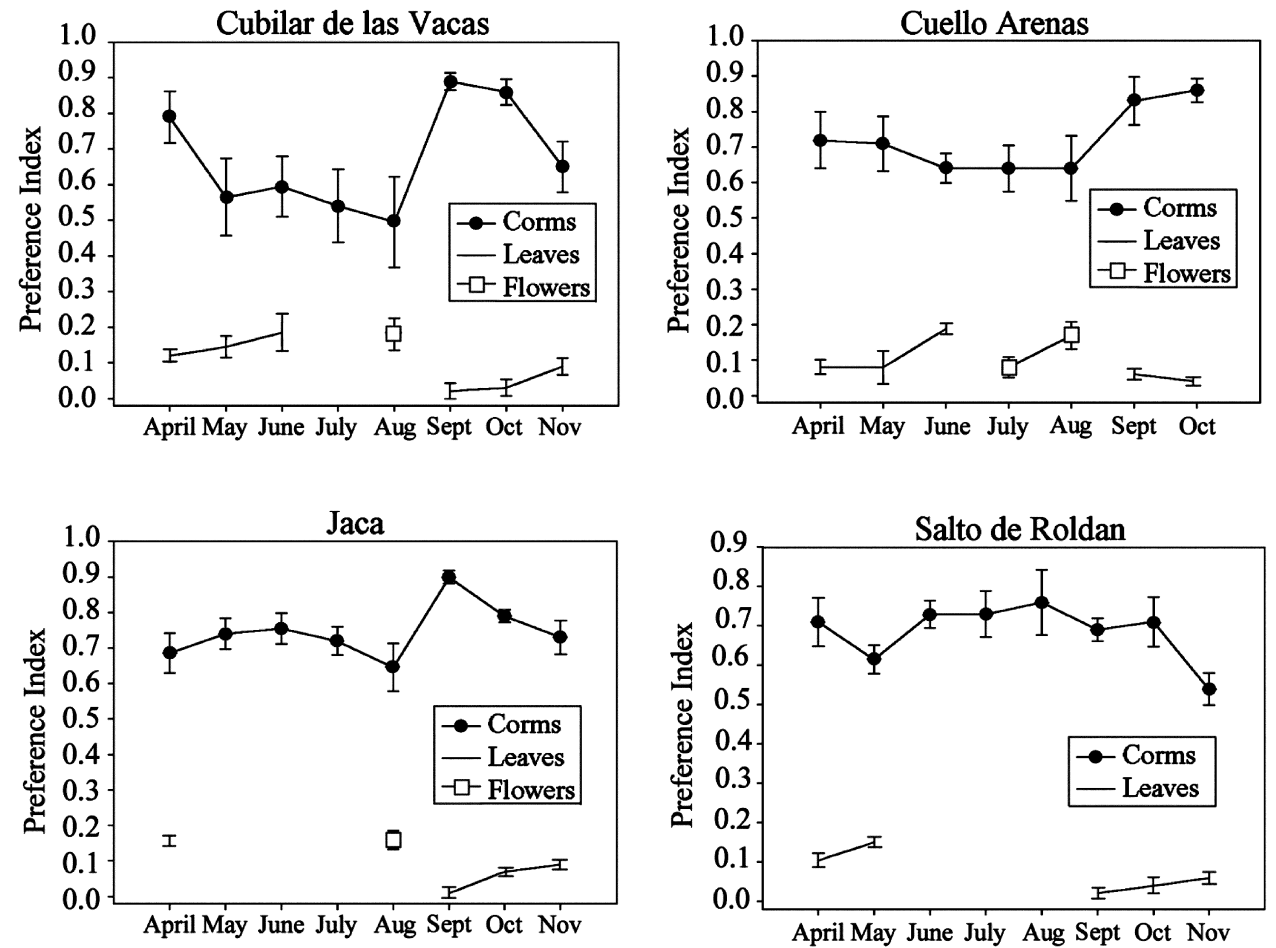

Figure 3. Median and standard error of preference index (Manly's $\alpha$ ) of mole-voles for corms, leaves and flowers of Merendera montana (L.) Lange from the different study areas.

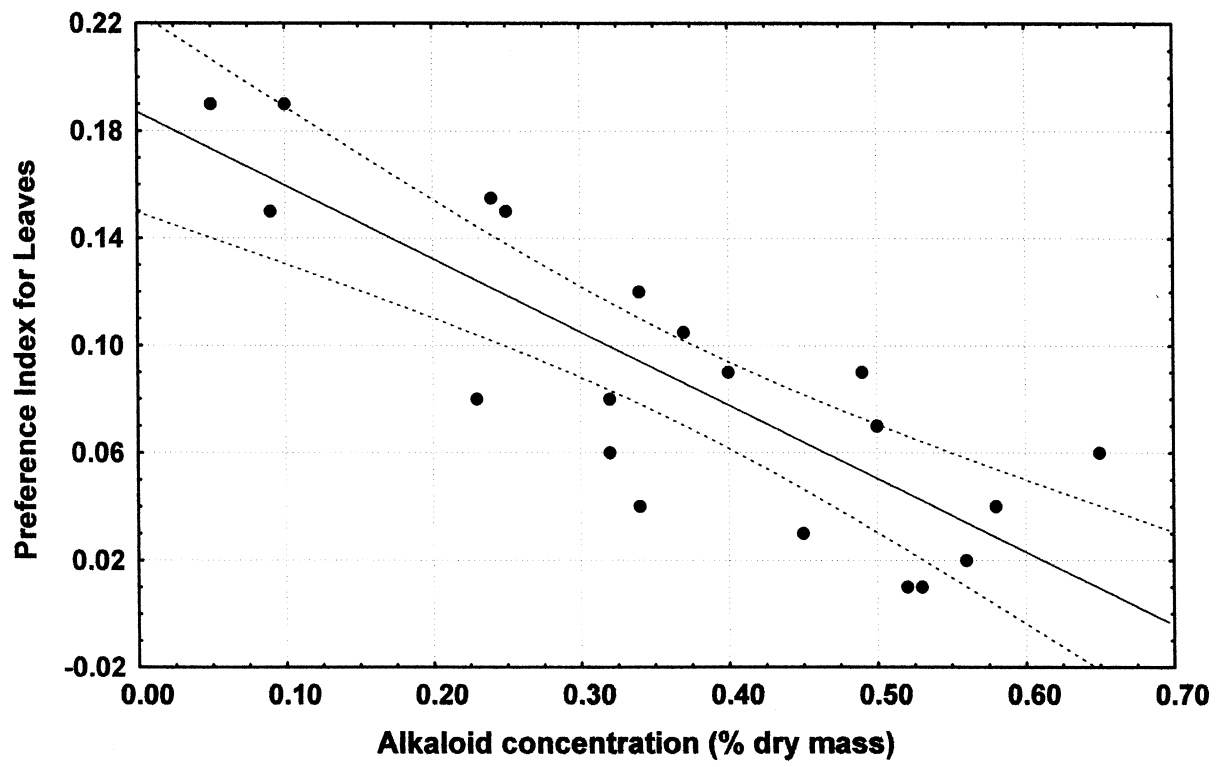

Figure 4. Correlation between preference index for leaves (Manly's $\alpha$ ) and alkaloid concentration (expressed as \% unit dry mass). Spearman correlation, $\mathrm{r}=-0.768, \mathrm{p}=0.00008, \mathrm{n}=20$.

\section{Acknowledgements}

N. Horak assisted us with the English version. The critical comments on an early manuscript of Dan Jan- zen, Ricardo García-González, Cindy Roché, Eduardo Martinez-Carretero and Claudia Campos are much appreciated. 


\section{References}

Bennett N.C. and Jarvis J.U.M. 1995. Coefficients of digestibility and nutritional values of geophytes and tubers eaten by southern Africa mole-rats (Rodentia: Bathyergidae). Journal of Zoology 236: 189-198.

Borghi C.E. 1992. The Subterranean Small Mammals of the Spanish Aragonian Pyrenees (subgen Pitymys): Impact on Soil Erosion and Vegetation. Doctoral thesis, University of Madrid, 167pp.

Borghi C.E. and Giannoni S.M. 1997. Dispersal of geophytes by mole-voles in the Spanish Pyrenees. Journal of Mammalogy 78: 550-555.

Brett R.A. 1991. The ecology of naked mole-rat colonies: burrowing, food and limiting factors. In: Sherman P.W., Jarvis J.U.M. and Alexander R.A. (eds), The Biology of the Naked Mole-Rat. Princenton University Press, New Jersey, USA, pp 512.

Canals R.M. and Sebastià M.T. 2000. Soil nutrient fluxes and vegetation changes on molehills. Journal of Vegetation Science 11: 23-30.

Collins S.L. and Barber S.C. 1985. Effects of disturbance on diversity in mixed-grass prairie. Vegetatio. 64: 87-94.

Contreras L.C. and Gutiérrez J.R. 1991. Effects of the subterranean herbivorous rodent Spalacopus cyanus on herbaceous vegetation in arid coastal Chile. Oecologia 87: 106-109.

Dafni A., Shmida A. and Avishai M. 1981. Leafless autumnalflowering geophytes in the Mediterranean region. Phytogeografical, ecological and evolutionary aspects. Plant Systematics and Evolution 137: 181-193.

Ellington E. 1998. Introducción de Colchicum autumnale L. al cultivo "in vitro" y estudio comparativo del contenido alcaloidico en especies silvestres de la familia Colchicaceae. Doctoral thesis, University of Barcelona, $237 \mathrm{pp}$.

Farnsworth N.R., Bingel A.S., Cordell G.A., Crane F.A. and Fong H.H.S. 1975. Potential value of plants as source of new antifertility agents II. Journal of Pharmaceutical Sciences 64: 717754.

Feeny P.P. 1976. Plant aparency and chemical defense. Recent Advances in Phytochemistry 10: 1-40.

Fell K.R. and Ramsden D. 1966. Phytochemical investigation of some species of Colchicum. Journal of Pharmacognosy and Pharmacology 18, Suppl: 126-132.

Freeland W.J. and Janzen D.H. 1974. Strategies in herbivory by mammals: The role of plant secondary compounds. American Naturalist 961: 269-289.

Galil J. 1967. On the dispersal of the bulbs of Oxalis cernua Thunb. by mole-rats (Spalax ehrenbergi Nehring). Journal of Ecology 55: 787-792.

García-González R. and Montserrat P. 1986. Determinación de la dieta de ungulados estivantes en los pastos supraforestales del Pirineo Occidental. In: Actas XXVI Reunión Científica de la S.E.E. Vol. 1. Consejería de Agricultura y Pesca, Oviedo, España, pp. 119-134.

Gómez-García D., Borghi C.E. and Giannoni S.M. 1995. Vegetation differences caused by pine vole mound building in subalpine plant communities in the Spanish Pyrenees. Vegetatio. 117: 61-67.
Gómez-García D., Giannoni S.M., Reiné R. and Borghi C.E. 1999. Movement of seeds by the burrowing activity of mole-voles in the Spanish Pyrenees. Arctic, Antarctic and Alpine Research 31: 407-411.

Goodall D.W. 1953. Point quadrat methods for the analysis of vegetation. Australian Journal of Botany 1: 457-461.

Harper J.L. 1977. Population Biology of Plants. Academic Press, London, England, 892 pp.

Hobbs R.J. and Hobbs V.J. 1987. Gophers and grassland: a model of vegetation response to patchy soil disturbance. Vegetatio. 69: 141-146.

Hobbs R.J. and Mooney H.A. 1991. Effects of rainfall variability and gopher disturbance on serpentine annual grasslands dynamics. Ecology 72: 59-68.

Huntly N. and Inouye R. 1988. Pocket gophers in ecosystems: patterns and mechanisms. BioScience 38: 786-793.

Huntly N. and Reichman O.J. 1994. Effects of subterranean mammalian herbivores on vegetation. Journal of Mammalogy 75: 852-859.

Kaul J.L., Moza B.K., Santavy F. and Vrublovsky P. 1964. Substances from the plants of the subfamily Wurmbaeoideae and their derivatives. LIX. Isolation of alkaloids from some plants of the subfamily Wurmbaeoideae. Collection of Czechoslvakia Chemical Communications 29: 1689-1701.

Krebs C.J. 1989. Ecological Methodology. Haper and Row, New York.

Lovegrove B.G. and Jarvis J.U. 1986. Coevolution between molerats (Bathyergidae) and a geophyte, Micranthus (Iridaceae). Cimbelasia (A) 8: 79-85.

Mathew B. 1982. The Crocus L. A Revision of the Genus Crocus L. Timber Press, Portland.

McKey D. 1974. Adaptative patterns in alkaloid physiology. American Naturalist 108: 305-319.

Murray B.D. and Dickman C.R. 1994. Granivory and microhabitat use in Australian desert rodents: are seeds important? Oecologia 99: 216-225.

Paris R.R. and Moyse H. 1967. Précis de Matiere Médicale. Vol. 3. Masson and Comp. Editeurs, Paris.

Pijewska L., Kaul J.L., Joshi R.K. and Santavy F. 1967. Substances from the plants of the subfamily Wurmbaeoideae and their derivates. The presence of alkaloids in some tribes of the subfamily. Collection Czecheslovaquia Chemical Communications 32: $158-170$

Poutaraud A. and Champay N. 1995. Le colchique (Colchicum autumnale L.): une plante medicinale à domestiquer. Revue Suisse d'Agriculture 27: 93-100.

Reichman O.J. and Jarvis J.U.M. 1989. The influence of three sympatric species of fossorial mole-rats (Bathyergidae) on vegetation. Journal of Mammalogy 70: 763-771.

Rhoades D.F. 1979. Evolution of plant chemical defense against herbivores. In: Rosenthal G.A. and Janzen D.H. (eds), Herbivores: Their Interactions with Secondary Plant Metabolites. Academic Press, New York, pp. 4-54.

Rhoades D.F. and Cates R.G. 1976. Toward a general theory of plant antiherbivore chemistry. Recent Advances in Phytochemistry 10: $168-213$.

Santavy F. 1957. Alkaloide der Colchicum-pflanzen. Pharmazie Zentralhalle 96: 307-333.

Soriguer R.S. and Amat J.A. 1980. On the structure and function of the burrows of the Mediterranean vole (Pitymys duodecimcostatus). Acta Theriologica 25: 268-270. 
Sousa W.P. 1984. The role of disturbance in natural communities. Annual Review of Ecology and Systematics 15: 353-391.

Summerhayes V.S. 1941. The effect of voles (Microtus arvensis) on vegetation. Journal of Ecology 29: 14-48.

Wagner H., Bladt S. and Zgainski E.M. 1984. Plant Drug Analysis. A Thin Layer Chromatography Atlas. Springer-Verlag, New York, Tokyo, pp. 320.
Watt J.M. and Breyer-Brandwijk M.G. 1962. The Medicinal and Poisonous Plants of Southern and Eastern Africa. 2nd edn. E and S Livingstone Ltd., Edinbourgh and London. 